\title{
Improvement of the Surface Layer of Steel Using Microwave Plasma Nitriding
}

\author{
Khyoupin Khoo ${ }^{1}$, Manabu Takeuchi ${ }^{2}$, Jin Onuki ${ }^{2}$ and Takao Komiyama ${ }^{3}$ \\ ${ }^{1}$ Graduate School of Science and Engineering, Ibaraki University, Hitachi 316-8511, Japan \\ ${ }^{2}$ Department of Materials Science, Faculty of Engineering, Ibaraki University, Hitachi 316-8511, Japan \\ ${ }^{3}$ Department of Electronic and Information Systems, Faculty of Systems Science and Technology, Akita Prefectural University, \\ Honjo 015-0055, Japan
}

Microwave plasma was employed for the nitriding of SCM445 steel and characteristics of the steel obtained by this process were compared with those of steel treated by conventional ion nitriding. The latter showed a large amount of globular shaped nitride compounds around $1-2 \mu \mathrm{m}$ size precipitated on the steel surface and surface coarsening after ion nitriding. However, microwave plasma nitriding successfully produced a nitrided steel without a compound layer and a diffusion layer thickness of more than $0.5 \mathrm{~mm}$ was achieved at gas composition of $30 \% \mathrm{~N}_{2}-70 \% \mathrm{H}_{2}$ $\left(500^{\circ} \mathrm{C}, 2 \mathrm{~h}\right)$. Also, a smooth surface was also achieved. Microwave plasma nitriding was capable of producing just the diffusion layer with a good surface condition for subsequent deposition of a protective coating.

(Received November 7, 2003; Accepted February 3, 2004)

Keywords: microwave, plasma, ion nitridng, diffusion layer, nitride compounds, SCM445 steel

\section{Introduction}

Nitriding for surface modifications of steels has been used industrially for the last 70 years and is widely accepted as a technology to improve the surface properties of metal components. ${ }^{1,2)}$ Plasma nitriding without formation of a nitride compound layer was developed for practical use as a new hardening process since plasmas can enhance the diffusion of nitrogen into the steels and reduce treatment times. ${ }^{3)}$ An additional attractive feature of plasma nitriding is its greater environmental cleanliness. ${ }^{3,4)}$ The main motivation of prior research has been to carry out nitriding and subsequent deposition of protective coatings on the nitrided surfaces in the same processing chamber. However, conventional nitriding processes such as ion nitriding ${ }^{5,6)}$ done using a glow discharge current are difficult to implement without the formation of a nitride compound layer at the steel surface. Nitrides tend to cause material failure when forming a mixed compound layer of both $\varepsilon-\mathrm{Fe}_{2-3} \mathrm{~N}$ and $\gamma^{\prime}-\mathrm{Fe}_{4} \mathrm{~N}$ phases. Nitrides also produce coarser surfaces and causes problems with the adhesion of hard protective coatings, which may be later deposited on nitrided steel. ${ }^{7)}$ Therefore, it is necessary to develop a nitriding process which forms only a diffusion layer at the surface region and produces a smooth surface for good adhesion of the hard coating layer.

In this study, the microwave plasma nitriding of steel was studied for ways to reduce the nitride compound layer formation and lessen surface roughness at the steel surface layer. Microwave plasma has advantages of giving a large degree of ionization, ${ }^{8)}$ and high plasma reactivity due to the effective production of active species at high electron temperatures and densities. ${ }^{9)}$ Therefore, the microwave plasma nitriding process was carried out to find optimum conditions for effective nitriding of alloyed steel. Surfaces of steel samples nitrided with microwave plasma and conventional ion nitriding were compared.

\section{Experimental Procedure}

A schematic diagram of the microwave plasma nitriding experimental setup is shown in Fig. 1. The microwave generator, working at the frequency of $2.45 \mathrm{GHz}$, could be operated at a power of up to $1.2 \mathrm{kw}$. The incident microwave power was changed from 100 to $140 \mathrm{~W}$, and the reflection power was adjusted below $10 \mathrm{~W}$ in order to produce the highest value of plasma density. No external bias voltage was

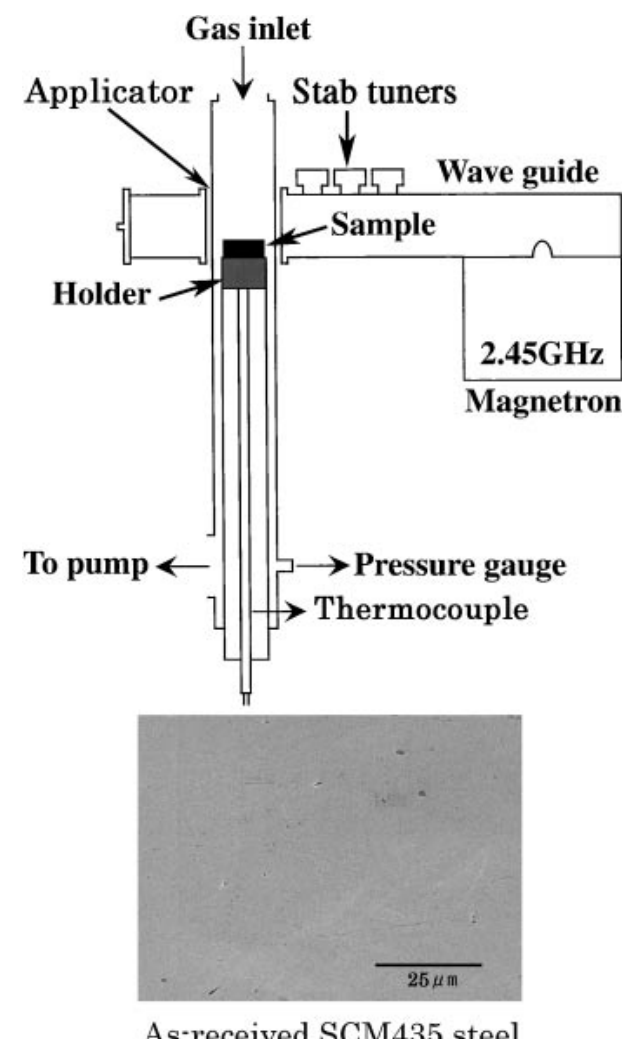

Fig. 1 Microwave plasma nitriding apparatus and SEM image of asreceived SCM435 steel. 
applied to the steel samples.

On the other hand, the conventional ion nitriding using glow discharge was conducted in an ion nitriding chamber that was connected to an anode. The steel samples were placed on the cathode which was located beneath the anode. A discharge voltage of $400 \mathrm{~V}$ and current of 50-130 mA were applied in ion nitriding. The temperature was regulated directly by the electrical power applied to the discharge.

For the ion and microwave plasma nitriding processes, a nitrogen and hydrogen mixed gas of $30 \% \mathrm{~N}_{2}-70 \% \mathrm{H}_{2}$ (199.5 Pa $\mathrm{N}_{2}-465.5 \mathrm{~Pa} \mathrm{H}_{2}$ ) or $50 \% \mathrm{~N}_{2}-50 \% \mathrm{H}_{2}$ (332.5 $\mathrm{Pa} \mathrm{N}_{2}$ $332.5 \mathrm{~Pa} \mathrm{H}_{2}$ ) was used. Nitriding was carried out for $2 \mathrm{~h}$ at a total pressure of 5 Torr. Nitriding temperatures for both processes were $400-550^{\circ} \mathrm{C}$ and measured using a thermocouple embedded inside the sample holder. The temperature fluctuation was controlled within $\pm 5 \mathrm{~K}$ during processing.

SCM445 steel in JIS (Japan Industrial Standard) was used as the substrate material for both nitriding processes. The chemical composition of the material was 0.44 mass $\% \mathrm{C}$, 0.25 mass $\% \mathrm{Si}, 0.73$ mass $\% \mathrm{Mn}, 0.92$ mass $\% \mathrm{Cr}, 0.13$ mass $\%$ Mo, 0.1 mass $\% \mathrm{Ni}, 0.018$ mass $\% \mathrm{P}, 0.011 \mathrm{mass} \% \mathrm{~S}$, and $\mathrm{Fe}$ as a balance. The steel was supplied in the plate condition, and it was annealed in $100 \% \mathrm{Ar}$ gas atmosphere at $680^{\circ} \mathrm{C}$ for $2 \mathrm{~h}$ with infrared furnace. Prior to nitriding, the steel samples were machined into a square shape of $9 \mathrm{~mm} \times 9 \mathrm{~mm}$ with a thickness of $3 \mathrm{~mm}$ and they were mirror-polished using \#6001200 silicon carbide paper and alumina powders $(0.3 \mu \mathrm{m}$ dia.). The samples were finally cleaned ultrasonically in acetone. The average surface hardness of as-received steel was $265 \mathrm{Hv}$.

The steel samples before and after ion and microwave plasma nitriding were studied by scanning electron microscopy (SEM) to identify the surface morphology changes. The crystal structure and lattice parameter of the nitrided layers were investigated by diffractometry using $\mathrm{CoK} \alpha$ with a accelerating voltage of $30 \mathrm{kV}$ and a tube current of $8 \mathrm{~mA}$. The hardness of the nitrided steels was measured with Vickers microhardness indenters utilizing $100 \mathrm{~g}$ loads.

\section{Results and Discussion}

A SEM image showing surface morphology of as-received SCM445 steel is shown in Fig. 1. After ion nitriding, the mirror surface of the samples became slightly grey and cloudy. However, samples treated by microwave plasma nitriding kept their luster.

Figure 2 shows surface morphologies and cross-sectional SEM images of SCM445 steel after ion and microwave plasma nitriding processes in $30 \% \mathrm{~N}_{2}-70 \% \mathrm{H}_{2}\left(199.5 \mathrm{~Pa} \mathrm{~N}_{2}\right.$ $465.5 \mathrm{~Pa} \mathrm{H}_{2}$ ) mixed gas at $500^{\circ} \mathrm{C}$ for $2 \mathrm{~h}$. A discharge voltage of $400 \mathrm{~V}$ and current of $100 \mathrm{~mA}$ were applied in ion nitriding and the incident microwave power of $125 \mathrm{~W}$ was applied in microwave plasma nitriding. The surface layer of ion nitrided steel included a large amount of globular shaped crystallites around $1-2 \mu \mathrm{m}$ size formed during ion nitriding and these precipitates increased the surface roughness as shown in Fig.
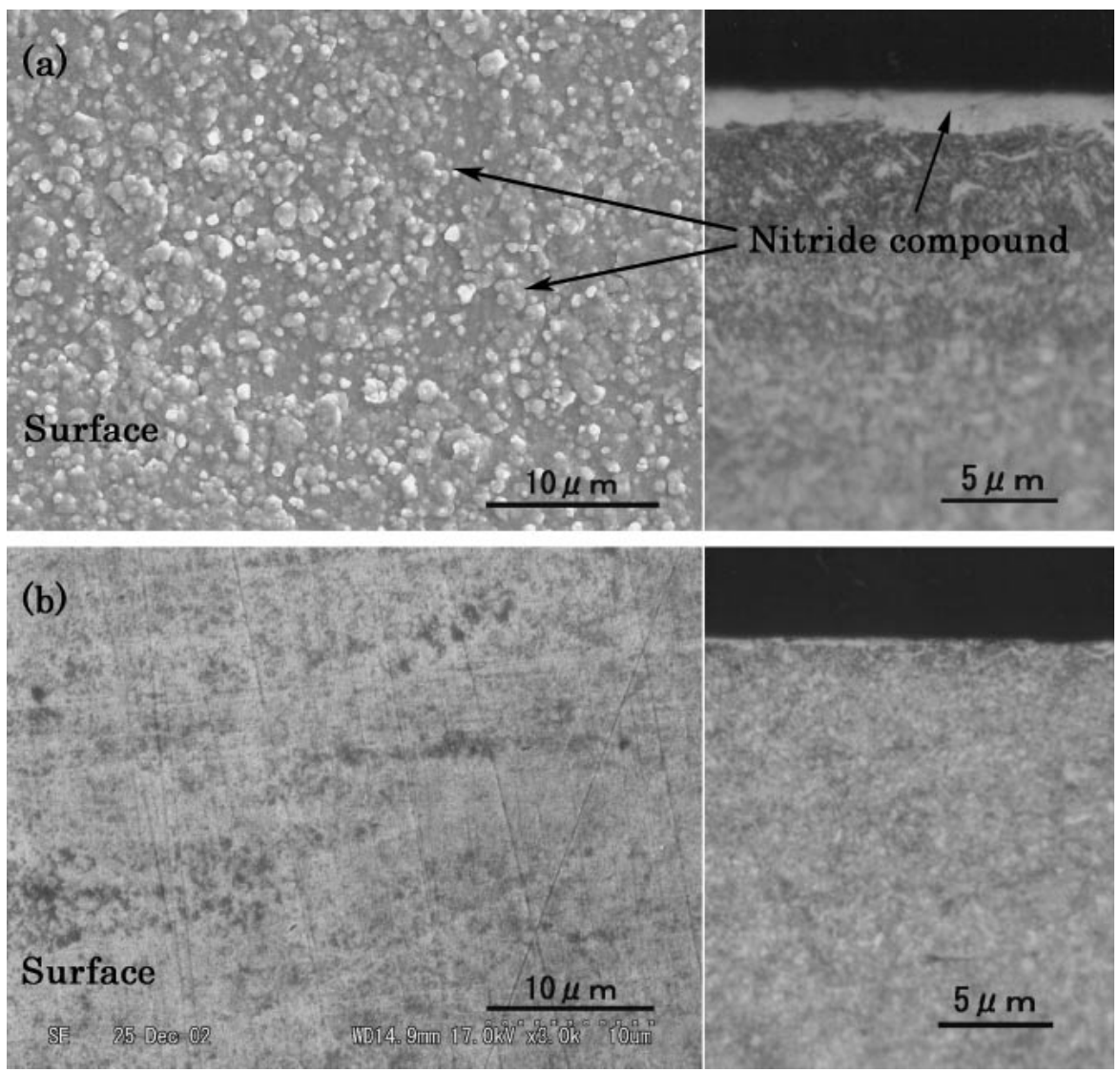

Fig. 2 SEM images of surface morphologies (left) and cross sections (right) of SCM435 steel after (a) ion nitriding and (b) microwave plasma nitriding processes in $30 \% \mathrm{~N}_{2}-70 \% \mathrm{H}_{2}$ at $500^{\circ} \mathrm{C}$ for $2 \mathrm{~h}$. A layer of fine globular shaped $\varepsilon-\mathrm{Fe}_{2-3} \mathrm{~N}$ and $\gamma^{\prime}-\mathrm{Fe}_{4} \mathrm{~N}$ compounds was formed over the nitrided surface by ion nitriding. 


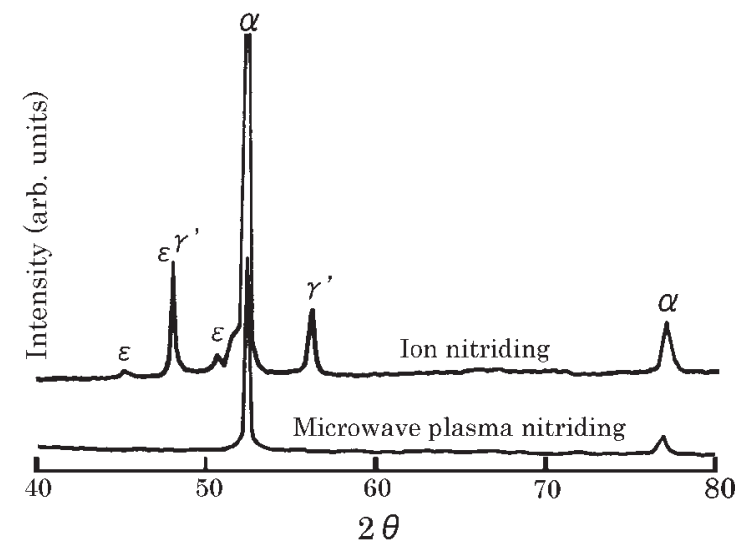

Fig. 3 XRD patterns of SCM435 steel nitrided by ion and microwave plasma processes in $30 \% \mathrm{~N}_{2}-70 \% \mathrm{H}_{2}$ at $500^{\circ} \mathrm{C}$ for $2 \mathrm{~h}$. No nitride compounds were detected from the microwave plasma nitrided SCM435.

2(a).

However, for the steel nitrided in microwave plasma, the entire surface remained clean and smooth as shown in Fig. 2(b) and no compound layer was formed. This result indicated that microwave plasma nitriding could suppress formation of the nitride compound layer on the nitrided surface.

Figure 3 shows X-ray diffraction patterns obtained from the SCM445 steel after ion and microwave plasma nitriding processes in $30 \% \mathrm{~N}_{2}-70 \% \mathrm{H}_{2}\left(199.5 \mathrm{~Pa} \mathrm{~N}-465.5 \mathrm{~Pa} \mathrm{H}_{2}\right)$ at $500^{\circ} \mathrm{C}$ for $2 \mathrm{~h} . \varepsilon-\mathrm{Fe}_{2-3} \mathrm{~N}$ and $\gamma^{\prime}-\mathrm{Fe}_{4} \mathrm{~N}$ compounds were formed for ion nitriding, while they were not formed for microwave plasma nitriding.

The steel surface became uneven and weak nitride compound peaks were observed from the XRD pattern for microwave plasma nitriding when the nitrogen concentration was increased to $50 \%$ as shown in Fig. 4. This suggested that the nitrogen concentration played an important role in microwave plasma nitriding. Hence, the nitrogen concentration of $30 \%$ or below was judged to be suitable for microwave plasma nitriding without formation of a nitride compound layer.

The cross-sectional hardness (Vicker's microhardness, $100 \mathrm{~g}$ load) of SCM445 steel samples after ion and micro-

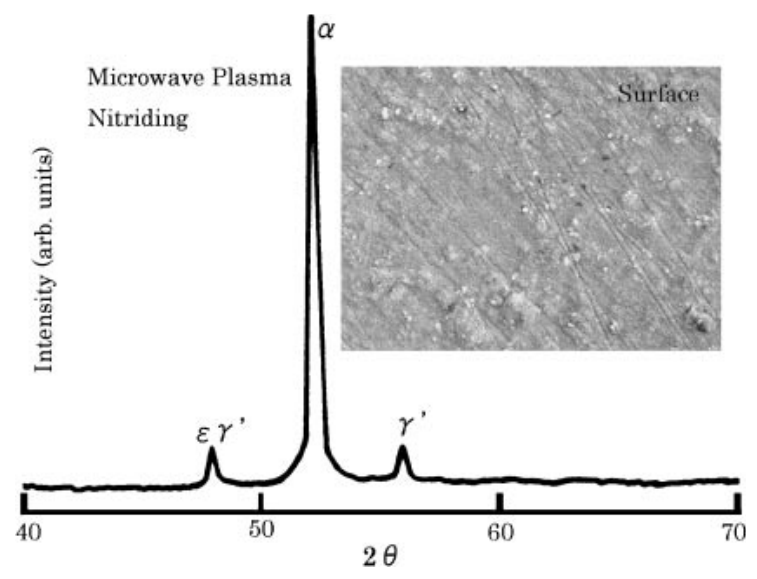

Fig. 4 XRD pattern and SEM image of surface morphology of the SCM435 steel after microwave plasma nitriding in $50 \% \mathrm{~N}_{2}-50 \% \mathrm{H}_{2}$ at $500^{\circ} \mathrm{C}$ for $2 \mathrm{~h}$.

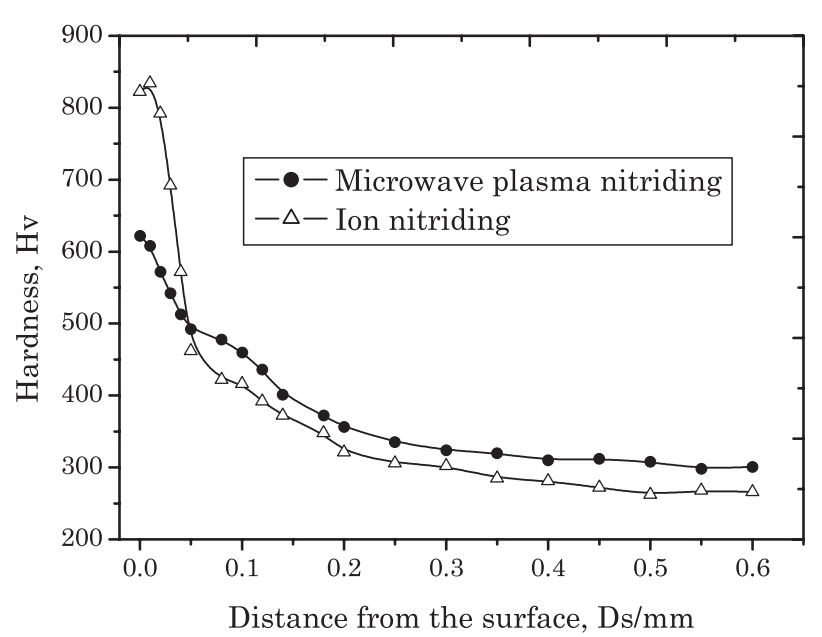

Fig. 5 Cross-sectional hardness of SCM435 steel as a function of distance from the surface after microwave plasma and ion nitriding processes in $30 \% \mathrm{~N}_{2}-70 \% \mathrm{H}_{2}$ at $500^{\circ} \mathrm{C}$ for $2 \mathrm{~h}$. The surface of ion nitrided steel had a hardness of approximately $842 \mathrm{Hv}$, which meant nitride compounds formed at the steel surface.

wave plasma nitriding processes in $30 \% \mathrm{~N}_{2}-70 \% \mathrm{H}_{2}$ at $500^{\circ} \mathrm{C}$ for $2 \mathrm{~h}$ is shown in Fig. 5. The surface of ion nitrided steel had a hardness of approximately $842 \mathrm{Hv}$ after ion nitriding, which was attributed to the formation of nitride compounds. ${ }^{10)}$ The surface hardness of microwave plasma nitrided steel was much lower than that of ion nitrided steel. However, in the inner range between $0.05-0.6 \mathrm{~mm}$, it was found that the hardness for microwave plasma nitrided steel was higher than that for the ion nitrided steel.

This observation can be explained as follows. When $\mathrm{N}_{2}$ and $\mathrm{H}_{2}$ mixing gases are ionized in the discharge current or in the microwave plasma, the ionized hydrogen ions interact with the steel surface leading to the reduction of oxide. ${ }^{11)}$ This increases the sticking coefficient for nitrogen ions at the steel surface, ${ }^{12)}$ which can effectively promote the diffusion of nitrogen into the inner region of the steel.

For ion nitriding, the reaction at the steel surface involves the sputtering and redeposition of ejected atoms. In the presence of electric field, the steel (cathode) is maintained at a negative dc voltage discharge with respect to the anode. Under the influence of bias, the nitrogen and hydrogen gases are dissociated, ionized, and accelerated to impinge on the cathode. The kinetic energy of ions is converted into thermal energy by ion bombardment, which not only heats the steel sample but also causes sputtering of Fe atoms from the steel surface. The ejected $\mathrm{Fe}$ atoms were then reacted with $\mathrm{N}$ ions to form high nitride $(\mathrm{FeN})$, followed by decomposition to lower nitrides $\left(\varepsilon-\mathrm{Fe}_{2-3} \mathrm{~N}\right.$ and $\left.\gamma^{\prime}-\mathrm{Fe}_{4} \mathrm{~N}\right)$ on the steel surface. ${ }^{3)}$ The formation of nitride compounds and energetic ion bombardment due to the dc glow discharge cause a coarser surface morphology.

On the other hand, the nitriding process due to microwave plasma may be explained as follows. Microwave plasma has advantages in generating high energy and high density of ions, ${ }^{8,9)}$ and the movement of ionized nitrogen and hydrogen ions is very small due to the high frequency used. Only electrons can move due to the potential changes in the microwave plasma ${ }^{14)}$ and the steel temperature is raised by 
the electron collisions. Therefore, a self-bias is applied to the steel samples and thus microwave plasma nitriding of steel is promoted by the accelerated nitrogen and hydrogen ions. ${ }^{13,14)}$ Due to the weak ionic bombardment in microwave plasma, the sputtering effect at the steel surface is considered to be very weak. Microwave discharges also have advantages for the generation of fast electrons which result in higher electron temperatures. ${ }^{89}$ ) The significantly higher electron temperature under the microwave plasma conditions is expected to provide more energy to be transferred to the steel surface but also to produce a more higher density and more energetic nitrogen atoms. ${ }^{8}$ Subsequently, the enhanced energetic nitrogen atoms would absorb at the steel surface and then diffuse faster into the matrix. Therefore, the nitriding depth in the diffusion layer is more significant for microwave plasma nitriding with hardness above $300 \mathrm{Hv}$ as shown in Fig. 5. This result indicated that the diffusion rate of nitrogen ions in microwave plasma nitriding was much higher than that in ion nitriding.

Figure 6 shows the influence of nitriding temperature and nitrogen concentration at the compound layer thickness for microwave plasma and ion nitriding processes. The compound layer thickness was the mean value of 10 points measured randomly. For microwave plasma nitriding, no compound layer was observed on the surface layer in the temperature range between $400^{\circ} \mathrm{C}$ and $550^{\circ} \mathrm{C}$ in $30 \% \mathrm{~N}_{2}$ $70 \% \mathrm{H}_{2}$. The incident microwave power was in the range from 100 to $140 \mathrm{~W}$. When nitrogen concentration was increased to $50 \% \mathrm{~N}_{2}-50 \% \mathrm{H}_{2}$, the compound layer thickness slightly increased for microwave plasma nitriding. However, the nitride compound layer formed with ion nitriding (discharge current, $400 \mathrm{~V}$; current, 50-130 mA) was much thicker than that with microwave plasma nitriding, and it increased substantially with temperature. Due to the stronger sputtering effect of discharge current, the compound layer thickness of ion nitrided steels which formed was much thicker than that of microwave plasma nitrided steels. Figure 6 further indicated that formation of the compound layer, suppressed mainly by reducing the nitriding temperature or by incorporating more $\mathrm{H}_{2}$ in the plasma, exerted a

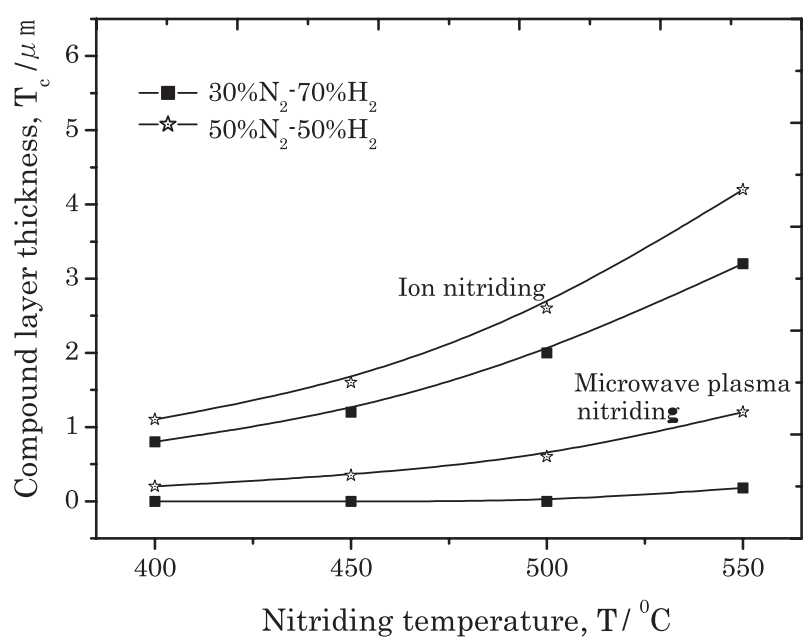

Fig. 6 Influences of nitriding temperature and nitrogen concentration on the thickness of the compound layer formed by ion nitriding and microwave plasma nitriding processes.

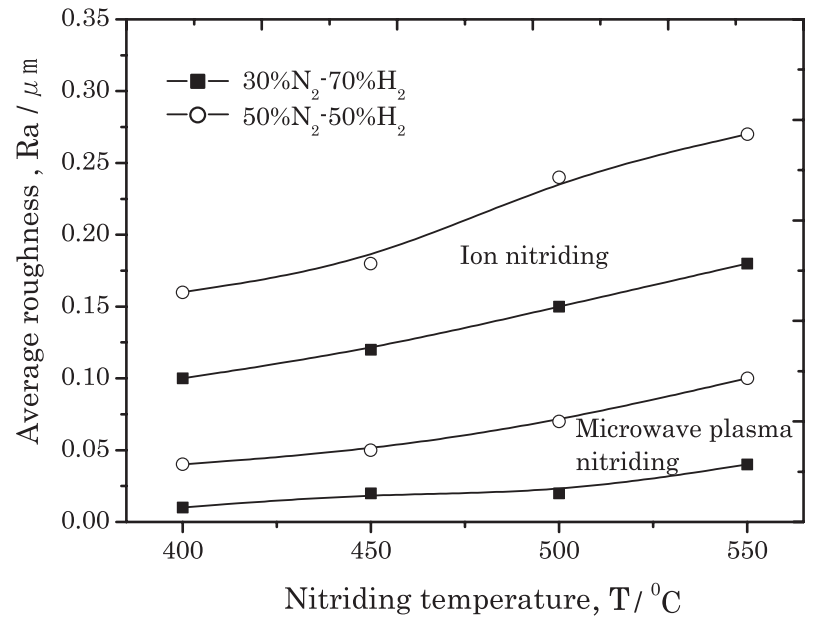

Fig. 7 Influences of nitriding temperature and nitrogen concentration on the average roughness of the nitrided surface for ion nitriding and microwave plasma nitriding processes.

controlling effect on the nitriding process. Suppression of the compound layer could compensate up to a point for the reduction in the nitrogen concentration introduced by a higher $\mathrm{H}_{2} / \mathrm{N}_{2}$ ratio or lower gas pressure. Thus, for the present nitrogen concentration $\left(30 \% \mathrm{~N}_{2}\right)$ these results indicated that there was an optimum combination between compound layer thickness and nitrogen concentration.

Figure 7 shows the influences of nitriding temperature and nitrogen concentration on the surface roughness change for both microwave plasma and ion nitriding processes. For microwave plasma nitriding, an average surface roughness below $0.04 \mu \mathrm{m}$ was achieved in the temperature range between $400^{\circ} \mathrm{C}$ and $550{ }^{\circ} \mathrm{C}$ in $30 \% \mathrm{~N}_{2}-70 \% \mathrm{H}_{2}$. The relatively smooth and even conditions of the steel surface were considered to be due to the weaker bombardment of ions for microwave plasma nitriding than for ion nitriding. As mentioned above, the acceleration of hydrogen and nitrogen ions is low in microwave plasma, so the impingement effect of nitrogen and hydrogen ions on the steel surface is expected to induce only a weak ionic bombardment. Therefore, there is less concern about damage from the microwave plasma compared to conventional ion nitriding, and the luster of steel can be kept after nitriding. At the gas composition of $50 \% \mathrm{~N}_{2}-$ $50 \% \mathrm{H}_{2}$, the surface roughness of steel samples increased with nitriding temperature for both microwave plasma and ion nitriding processes.

The results of the present study showed that controlling nitriding temperature and concentration of nitrogen in the $\mathrm{N}_{2}$ and $\mathrm{H}_{2}$ gas mixture could suppress the formation of a compound layer on the steel surface for the microwave plasma nitriding method. Only the diffusion layer was formed at the steel surface region and a smooth surface was achieved. Hence no removal of a nitride compound layer from the nitrided surface would be needed before applying a protective coating.

\section{Conclusions}

Microwave plasma was employed for the nitriding of SCM445 steel and the characteristics of the steel obtained by 
this method were compared with those for steel treated by ion nitriding. A large amount of globular shaped nitride compounds was precipitated at the surface when ion nitriding was used and they caused surface roughness. However, microwave plasma nitriding successfully produced a nitrided steel without a compound layer and a diffusion layer thickness of more than $0.5 \mathrm{~mm}$ was achieved for a gas composition of $30 \% \mathrm{~N}_{2}-70 \% \mathrm{H}_{2}$ at $500^{\circ} \mathrm{C}$ for $2 \mathrm{~h}$. It was also observed that the microwave plasma was capable of producing a flat and smooth surface. The microwave plasma nitriding process was confirmed to be suitable for diffusion layer formation with no compound layer. Microwave plasma nitriding would be suitable for producing a good surface condition for subsequent deposition of a protective coating on nitrided steel.

\section{REFERENCES}

1) ASM Committee on Gas Carburizing, Carbonitriding, and Nitriding,
Gas Nitriding, Heat Treatment: ASM Handbook, 4, American Society of Metals, Materials Park, OH, (1991) 191.

2) M. B. Karamis and E. Gerçekcioğlu: Wear 243 (2000) 76-84.

3) B. Edenhofer: Heat Treat. Met. 1 (1974) 23.

4) A. M. Staines and T. Bell: Thin Solid Films 86 (1981) 201-212.

5) K. P. Khoo, R. I. Urao, I. Y. Oshima and K. Y. Terakado: Surface Modification Technologies 13 (1999) 13-19.

6) L. Petitjean and A. Ricard: J. Phys. D. Appl. Phys. 17 (1984) 919-929.

7) E. I. Meletis and S. Yan: J. Vac. Sci. Technol. A11 (1993) 25-33.

8) J. Hopwood, D. K. Reinhard and J. Asmussen: J. Vac. Sci. Technol. A8 (1990) 3103-3112.

9) Y. Weng and M. J. Kushner: J. Appl. Phys. 72 (1992) 33-42.

10) P. C. Jindal: J. Vac. Sci. Technol. 15 (1978) 313-317.

11) A. Leyland, K. S. Fancey and A. Matthews: Surf. Engin. 7 (1991) 207210.

12) A. Szasz, D. J. Fabian, A. Hendry and Z. Azaznc-Csih: J. Appl. Phys. 66 (1989) 5598-5601.

13) T. Shibata and T. Koshijima (editors): Microhakanetugijyutusyusei NTS (1994) 124 (In Japanese).

14) F. F. Chen: Phys. Plasmas 2 (1995) 2164-2175. 